Estudios Constitucionales, Año 10, No 2, 2012, pp. 609 - 616.

ISSN 0718-0195

Centro de Estudios Constitucionales de Chile Universidad de Talca

"Sobre la Constitución viviente"

Miguel Carbonell

\title{
SOBRE LA CONSTITUCIÓN VIVIENTE
}

Miguel Carbonell ${ }^{1}$

IIJ-UNAM

En varios países de América Latina estamos siempre ocupados (y preocupados) por las constantes reformas constitucionales, que sin pausa y sin tregua han ido modificando nuestras Cartas Magnas a un ritmo increíble durante las últimas décadas. En otros países, como por ejemplo en Estados Unidos, la preocupación surge precisamente por el motivo contrario: por la falta de movilidad de su texto constitucional, derivado de las dificultades que se tienen para llevar a cabo la reforma ${ }^{2}$.

Cuando una constitución tan antigua en el tiempo como lo es la norteamericana no puede ser actualizada a través del mecanismo de reforma, lo que se impone es discutir hasta qué punto resulta indispensable una interpretación constitucional evolutiva, que permita dotar al texto del sentido de realidad y de contemporaneidad que logre evitar su natural desgaste.

A partir de que se reconoce la pertinencia de una metodología interpretativa de carácter evolutivo es que surge el concepto de "Constitución viviente" ("living constitution”, en inglés). Una Constitución viviente, dice David Strauss, es una constitución que evoluciona, que cambia con el paso del tiempo y que se adapta a las nuevas circunstancias, pese a que no es formalmente modificada a través del procedimiento de reforma constitucional ${ }^{3}$.

Se trata de un concepto plausible, considerando que todos deseamos que el derecho en general vaya acompasado con el cambio social, dadas las enormes

\footnotetext{
${ }^{1}$ Licenciado en Derecho por la Facultad de Derecho de la UNAM. Doctor en Derecho por la Universidad Complutense de Madrid, España. Investigador del Instituto de Investigaciones Jurídicas de la UNAM. Coordinador del Área de Derecho Constitucional y de la Unidad de Extensión Académica y proyectos Editoriales del mismo Instituto. Investigador Nacional nivel III del Sistema Nacional de Investigadores desde enero de 2005.

${ }^{2}$ Un estudio muy amplio sobre los problemas y dilemas de la reforma constitucional en los Estados Unidos puede verse en Levinson, Sandford (editor), Responding to imperfection. The theory and practice of constitutional amendment, Princeton University Press, Princeton, 1995.

3 Strauss, David, The living constitution, Oxford University Press, Nueva York-Oxford, 2010.
} 
desventajas que tiene el que el orden jurídico se quede atrás respecto a la realidad. Pero en Estados Unidos el concepto de "Constitución viviente" ha sido duramente contestado.

Dicen sus críticos que aceptar que una constitución pueda sufrir cambios por vía interpretativa, sin ser formalmente enmendada, genera enormes riesgos. La Constitución viviente, dicen quienes discrepan, permite que su texto sean manipulable. Además, la adaptación del texto constitucional a la realidad, ¡en manos de quién recae? ¡estamos seguros que quienes interpretan la forma en que la carta suprema debe cambiar lo hacen de buena fe o a través de interpretaciones adecuadas, o bien podemos pensar que -por el contrario- lo hacen con base en sus propias ideas y planes políticos? ${ }^{34}$

Las tesis contrarias a la idea de la Constitución viviente se agrupan bajo la etiqueta del "originalismo", que propugna interpretar la Constitución de forma estricta, según sus palabras o según la intención de los redactores del texto 5 . Para los originalistas, no hay dilema alguno que resolver ya que la Constitución -a pesar de haber sido escrita hace más de 200 años- sigue ofreciendo respuestas adecuadas a los problemas del presente.

David Strauss analiza con detalle las posturas que defiende el originalismo y las confronta con las propuestas del constitucionalismo viviente. Lo que nos muestra es un fresco de gran calidad en cuyo fondo se encuentra el tema más importante de la teoría constitucional de nuestros días: la interpretación de las normas supremas.

Strauss parte de una evidencia: el procedimiento para reformar la Constitución de los Estados Unidos es tan complejo que, a estas alturas, resulta impracticable ${ }^{6}$. A partir de ahí la pregunta interesante es: ¿`cómo reconciliar los límites que impone una constitución escrita (y por tanto estática en su texto, en ausencia de reformas al mismo), con una realidad dinámica y siempre cam-

\footnotetext{
${ }_{4}^{4}$ Sobre el razonamiento judicial, de entre las muchas obras que se podrían citar, quizá valga la pena revisar el libro de Posner, Richard, How judges think, Harvard University Press, Cambridge, 2008.

${ }^{5}$ El originalismo tiene entre sus defensores más conocidos al juez de la Suprema Corte de los Estados Unidos Antonin Scalia, de quien puede verse el libro A matter of interpretation. Federal courts and the law, Princeton University Press, Princeton, 1997 (en la obra se incluye la crítica que destacados profesores le hacen a Scalia).

${ }^{6}$ No es algo que solamente suceda en Estados Unidos. Tampoco en España han logrado generar los cambios que, al parecer, requiere el texto constitucional de 1978. Sobre el procedimiento de reforma constitucional en España puede verse el clásico estudio de De VegA, Pedro, La reforma constitucional y la problemática del poder constituyente, Madrid, Tecnos, 1991.
} 
biante, de forma que la carta suprema pueda ir acompañando a la sociedad a través de los múltiples cambios que experimenta?

Obviamente, si todas las cláusulas constitucionales fueran claras en su significado, los problemas serían mucho menores. Algunas de ellas desde luego que lo son, pues contienen mandatos específicos cuyo significado no da lugar a grandes debates. Pero la mayor parte de las normas constitucionales están redactadas en forma de principios y, en esa virtud, su contenido preciso no es fácil de determinar ${ }^{7}$. Para poder aplicar esas normas a casos prácticos, se debe necesariamente llevar a cabo una interpretación: ¿de qué tipo debe ser esa interpretación? ¿debe ser apegada al texto original y a los deseos de sus autores, o debe tomar en cuenta lo que ha cambiado la sociedad? Ese es el dilema que nos pone enfrente Strauss.

Lo cierto es que una interpretación originalista estricta chocaría con varios de los criterios jurídicos más asentados que existen en los Estados Unidos. Strauss señala que si el originalismo fuera la doctrina imperante, la segregación racial en las escuelas estaría permitida, el gobierno podría discriminar a las mujeres y a las minorías raciales, la declaración de derechos (Bill of rights) no se les aplicaría a las entidades federativas, los gobiernos locales podrían violar el principio de "una persona, un voto", gran parte de la legislación laboral, ambiental y de protección de consumidores sería declarada inconstitucional, etcétera. Nada de eso es aceptable hoy en día para la sociedad de los Estados Unidos; el originalismo no es, por tanto, una teoría de la interpretación constitucional que ofrezca resultados positivos o constructivos.

Strauss señala que el originalismo tiene tres problemas fundamentales: a) en la práctica no siempre es fácil descubrir las intenciones de quienes redactaron un texto constitucional; b) aunque pudiéramos descubrir las intenciones originales de quienes redactaron la Constitución, tendríamos el reto de intentar aplicar esas intenciones a problemas de nuestros días, algunos de los cuales no pudieron ser previstos en su momento por la generación constituyente, y c) el tercer problema ya había sido avizorado hace mucho tiempo por Thomas Jefferson, cuando dijo que el mundo pertenece a los vivos y que las generaciones muertas no tienen derechos: ¿por qué deberíamos resolver problemas

\footnotetext{
${ }^{7}$ Una caracterización muy conocida de las normas iusfundamentales redactadas en forma de principios puede verse en ALEXY, Robert, Teoría de los derechos fundamentales, 2a edición, Madrid, CEPC, 2007, pp. 63 y siguientes.
} 
actuales siguiendo el criterio de personas que murieron hace muchos años? ¿qué ventajas obtenemos al hacerlo?

Es precisamente en una carta que Jefferson escribe al gran James Madison donde mejor se plasma su idea de que "la tierra pertenece a los vivos". Escribiendo desde París, donde era embajador de los Estados Unidos, Jefferson le dice a Madison en una misiva del 6 de septiembre de 1789 que "los vivos tienen la tierra en usufructo; y los muertos no tienen poder ni derechos sobre ella. La porción que ocupa un individuo deja de ser suya cuando él mismo ya no es, y revierte a la sociedad... ninguna sociedad puede hacer una constitución perpetua, ni tan siquiera una ley perpetua. La tierra pertenece siempre a la generación viviente: pueden, por tanto, administrarla, y administrar sus frutos, como les plazca, durante su usufructo... toda constitución, y toda ley, caducan naturalmente pasados treinta y cuatro años"8.

En respuesta a Jefferson, también por medio de una carta, Madison expresa sus dudas sobre la conveniencia de reformar con tanta frecuencia un texto constitucional o de darlo por caducado por el simple relevo generacional. Se pregunta Madison en una carta del 4 de febrero de 1790: “¿Un Gobierno reformado con tanta frecuencia no se haría demasiado mutable como para conservar en su favor los prejuicios que la antigüedad inspira y que tal vez constituyen una saludable ayuda para el más racional de los Gobiernos en la más ilustrada era? ¿No engendraría tan periódica revisión facciones perniciosas que de otra manera no podrían cobrar experiencia?".

La supervivencia de una forma de gobierno debe hallarse, dice Madison, en la utilidad que le pueda suponer para las generaciones futuras; si dicha utilidad no existe, entonces habrá que cambiar la forma de gobierno, pero eso no es algo que se pueda predeterminar con una temporalidad acotada, como lo propone Jefferson. Sigue Madison: "Las mejoras introducidas por los muertos constituyen una carga para los vivos que sacan de ellas los correspondientes beneficios. Esta carga no se puede satisfacer de otra manera más que ejecutando la voluntad de los muertos que acompañaba a las mejoras".

La conclusión de Madison es que una generación puede y debe obligar a las siguientes, siempre que de tales obligaciones se obtengan beneficios. Sus palabras son las siguientes: "Parece haber fundamento en la naturaleza de las

${ }^{8}$ Jefferson, Thomas, Autobiografía y otros escritos, Madrid, Tecnos, 1987, pp. 517-521. Una buena selección del pensamiento del autor puede encontrarse en Jefferson, Thomas, Writings, Nueva York, The Library of America, 1984 (hay reimpresiones posteriores). 
cosas en orden a la relación en que está una generación con otra, en particular en cuanto al traspaso de obligaciones de una a otra. Lo exige la equidad, y de ello derivan beneficios para una y otra generación. Todo lo que es necesario en lo que hace al ajuste de las cuentas entre los muertos y los vivos es ver que las deudas deparadas a éstos no excedan de las ventajas creadas por los primeros".

Respecto a la primera de las tres dificultades señaladas, Strauss nos recuerda algo muy obvio: indagar sobre las intenciones originales que tuvieron algunas personas que vivieron hace cientos de años es una tarea propia de historiadores. Si les pedimos a los jueces que lleven a cabo esa tarea lo más seguro es que consigamos un resultado muy pobre. Si comprender las intenciones de muchos actores políticos puede ser muy complicado en la actualidad; pero tal dificultad se multiplica y crece cuando lo que buscamos son intenciones de personas que habitaron la tierra hace mucho tiempo.

Ahora bien (en referencia a la segunda dificultad), si pudiéramos en efecto determinar el significado preciso que los autores del texto constitucional le quisieron dar a alguna de sus disposiciones, ¿cómo trasladamos esa intención a los problemas que nosotros tenemos que resolver en el presente? ¿qué pasa si descubrimos que las circunstancias del presente son tan radicalmente distintas a las de la época constituyente como para que resulte mejor no hacerle caso a la intención original de los redactores de la Carta Magna? ¿qué sucede si haciéndoles caso llegamos a soluciones que son negativas para las personas que hoy en día habitan la tierra?

Strauss señala que la preocupación de los originalistas para que los jueces no puedan manipular libremente la Constitución es legítima, pero la respuesta no es voltear al pasado en busca de significados remotos, como lo proponen los propios originalistas. La mejor respuesta para dicha preocupación está en la tradición histórica del common law, que le da una gran importancia al precedente. De hecho, la mayor parte de las sentencias de los jueces norteamericanos se apoyan en decisiones anteriores, sobre las cuales se van decantando las mejores respuestas a los casos concretos que deben irse resolviendo.

Los jueces están vinculados en principio a observar el precedente. Si deciden abandonar un criterio anterior deben hacerlo de manera expresa

\footnotetext{
9 Todas las citas provienen de MAdison, James, República y libertad, Madrid, CEPC, 2005, pp. $102-$ 103. El mismo documento y otros del mayor interés pueden verse en MADISON, James, Writings, Nueva York, The Library of America, 1999.
} 
y dando las razones de dicho abandono. Ese sistema de precedentes genera una cierta estabilidad interpretativa y acota de forma muy significativa los posibles márgenes de discrecionalidad judicial (aunque no los elimina, desde luego).

Las técnicas interpretativas propias del common law combinan, dice Strauss, una actitud humilde frente al precedente, y una sabiduría práctica que lleva a los jueces a preguntarse: ¿qué solución nos ofrece mejores resultados prácticos? Los jueces en el common law no se preocupan por cuestiones teóricas o por la compatibilidad de sus puntos de vista con lo que señalan los teóricos en sus libros y sus conferencias: les interesa llegar a la justicia en los casos concretos, aportando bienestar a las comunidades a las que sirven.

La interpretación basada en los principios del common law es mejor que la postura originalista, afirma Strauss, ya que no requiere que los jueces intenten hacerse pasar por historiadores. Además, el common law permite ir destilando una cierta "sabiduría judicial", a través de la confección, respeto y evolución del sistema de precedentes. Por otro lado, el common law permite resolver los problemas de hoy sin ir en busca de las intenciones que se tuvieron hace siglos, con lo cual demuestra una mayor razonabilidad frente al presente.

Ahora bien, ni la idea de la Constitución viviente ni las técnicas interpretativas propias del common law hacen a un lado u obscurecen la enorme importancia que tiene el texto constitucional escrito. Strauss defiende que la Constitución escrita aporta enormes ventajas, como por ejemplo la de crear un punto de encuentro, un terreno común, para discutir los problemas que van surgiendo en las sociedades a las que el documento pretende regir. En ausencia de ese terreno común una sociedad podría entrar en una espiral de desencuentros negativos y, en un supuesto extremo, autodestructivos.

En algunos casos, señala Strauss, la Constitución no ofrece respuestas a los problemas que tenemos. En otros solamente se limita a señalar el tipo de respuestas que serían aceptables desde el punto de vista constitucional. En otros más, cabe añadir, la Constitución sirve de marco para establecer el tipo de respuesta que no se le puede dar a ciertos problemas.

La combinación entre cláusulas específicas y cláusulas generales es parte de la genialidad de la Constitución de los Estados Unidos, según Strauss. La Constitución es específica cuando tiene que serlo, pero preserva márgenes razonables de apertura para que cada generación vaya ofreciendo sus propias respuestas a una serie de problemas que aparecen cada determinado tiempo. En los temas en que esa apertura existe es precisamente en los que los jueces 
y demás aplicadores del texto constitucional deben aportar argumentos para construir un terreno común de acuerdos y no de disensos. Las buenas constituciones sirven para construir respuestas valoradas por los ciudadanos y útiles al conjunto de la sociedad, no para dividirla y enfrentar a los grupos que la componen.

Desde luego, encontrar ese terreno común no es cosa fácil. Por eso la teoría contemporánea del derecho ha dedicado tantas y tantas páginas al tema de la interpretación jurídica en general y de la interpretación constitucional en particular. Es precisamente en vista de tales dificultades que tener un panorama claro de las distintas escuelas de interpretación, como el que nos ofrece David Strauss respecto al enfrentamiento entre los originalistas y los defensores de la Constitución viviente, es muy importante. De otra manera es posible que terminemos extraviados, en la búsqueda de ese terreno común que nos debe suministrar el constitucionalismo moderno, para hacer frente a los grandes problemas que padecen muchos países alrededor del mundo. 
